\title{
Cultural influences upon health, affect, self-esteem and impulsiveness: An Indonesian-Swedish comparison
}

Adrianson, Lillemor $\$
School of Education and Behavioral Sciences, University of Boras, Sweden (Iillemor.adrianson@ hb.se)

Ancok, Djamaludin

Faculty of Psychology, Gadjah Mada University, Indonesia (ancokpsi@ugm.ac.id)

Ramdhani, Neila

Faculty of Psychology, Gadjah Mada University, Indonesia (neila_psi@ugm.ac.id)

Archer, Trevor

Department of Psychology, University of Gothenburg, Sweden (trevor.archer@hb.se)

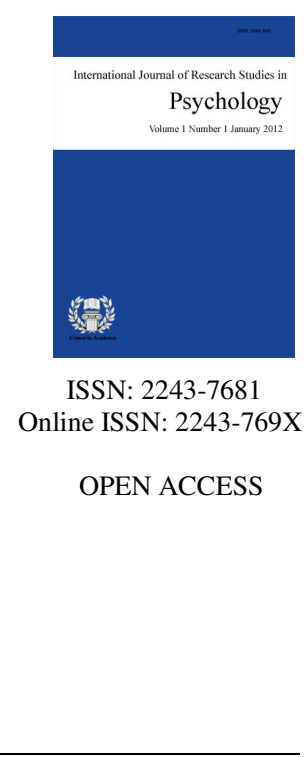

\section{Abstract}

The present study examines several personal attributes that distinguish the personal profiles of individuals, from Indonesian and Swedish cultures, according to self-reports of positive and negative effect, stress and energy, self-esteem, hospital anxiety and depression, dispositional optimism and health. Indonesian participants expressed both more PA and more NA than Swedish participants but less stress and a higher energy-stress quotient than the Swedish participants. Additionally, the former expressed a higher level of optimism and self-esteem, but also more depression, and less impulsiveness than the latter. Younger participants expressed less positive affect and more negative affect and impulsiveness than older participants who expressed both more stress and a higher energy stress quotient. Regression analyses indicated that PA was predicted by optimism and health whereas NA was predicted by anxiety and depression and impulsiveness and counter predicted by health. The present findings are discussed according to the notion of emotional regulation according to which individuals differ in their use of emotion regulation strategies such as reappraisal and suppression, and these individual differences have implications for affect, well-being, and social relationships.

Keywords: culture; age; affect; impulsiveness; self-esteem; optimism; stress; health 


\section{Cultural influences upon health, affect, self-esteem and impulsiveness: An Indonesian-Swedish comparison}

\section{Introduction}

Stress and /or situations associated with stress appear to accompany many aspects of an individual's everyday life and it seems undeniable that stress influences individuals' psychological and physical health negatively (Friedman et al., 1992). In the clinical setting, negative stress has been described as dysregulation in melancholic and atypical depression involving the secretion of glucocorticoids and other biomarkers (Gold \& Chrousos, 2002; Sachar et al., 1973), and even aspects of stress with more positive associations may induce negative consequences for individuals if maintained chronically without intervals for sufficient rest and recuperation (McEwen, 2006; Sapolsky, 2005). The dangers of chronic stress are expressed in a multitude of psychological and somatic factors (Ljung \& Friberg, 2004; Putman, Antypa, Crysovergi, \& van der Does, 2010). Self-reported data concerning stress/distress is associated generally with negative affective states, and both positive affect (PA) and negative affect (NA) may possess explanatory value, despite these scales being correlated with different factors (Andersson-Arntén, Jansson, \& Archer, 2008; Karlsson \& Archer, 2007). Both PA and NA influence individuals' relations to stressors, situations associated with stress and the experience of stress, as well as aspects of personality that imply greater risk for stress.

\subsection{Impulsiveness}

Decision-making is not necessarily a rational and conscious process but rather, implicitly or explicitly, the final result of cognitive-emotional profiles of individuals and the particular situations confronting them under conditions of health and disorder (Bechara, Damasio, Tranel, \& Damasio, 1997; Cohen \& Aston-Jones, 2005; Damasio, 1998; Sanfey, Rilling, Aronson, Nystrom, \& Cohen, 2003). Decision-making may be bolstered or rendered irresolute by emotion-linked stimuli, so-called "somatic markers", that may occur prior to complete consciousness as a function of choice suitability. For example, in the Iowa Gambling task (IGT) healthy subjects select cards from all four decks but learn quickly to rely on the advantageous decks and display greater anticipatory skin conductance responses prior to selecting a card from the disadvantageous deck (Bowman, Evans, \& Turnbull, 2005). The immediate gratification of desires at the expense of long-term goals in decision-making is characterized by high levels of impulsiveness and poor decisions that distinguish all neuropsychiatric conditions (Dolan \& Rennie, 2007; Krain et al., 2006; Lynskey \& Hall, 2001). Normal healthy individuals, under the influence of alcohol, make impulsive choices without regard for the consequences of these choices, persisting with higher wagers (Kyngdon \& Dickerson, 1999).

Individuals expressing higher levels of impulsiveness often display deficits over a variety of executive function tests (Dolan \& Park, 2002; Rogers et al., 2003), cognitive tasks involving response control (Potter \& Newhouse, 2004) and cognitive flexibility (Emanuele, Brondino, Bertona, Re, \& Geroldi, 2008; Keilp, Sackeim, \& Mann, 2005). The efficient and effective regulation of impulsiveness is an essential prerequisite for advantageous decision-making (Millet \& Sandberg, 2003). Lee, Leung, Fox, Gao and Chan (2008) employed event-related functional magnetic resonance imaging to study the differential neural activity associated with a "Risky-Gains" task in 18 healthy individuals divided into Low (n=9) or High (n=9) impulsiveness groups, according to scoring on the Barratt Impulsiveness Scale (BIS, Patton, Stanford, \& Barratt, 1995). They obtained greater brain activation in the insula-orbitofrontal-parietal region in the "high-impulsiveness" group but no differences between the groups in lateral prefrontal and anterior cingulate regions of the frontal lobe. Their results suggest that comprehension of cognitive and affective information linked to risk-taking decision-making activates different brain regions as a function of the impulsive tendencies of healthy individuals. 


\subsection{Self-esteem}

Self-esteem has been found to influence individuals' perceptions of events and situations as well as cognitive appraisals and responses under a variety of circumstances that involve stress to greater or lesser extent (Baumeister \& Tice, 1985; Bensink, Godbey, Marshall, \& Yarandi, 1992; Cannella, Lobel, Glass, Lokshina, \& Graham, 2007). Self-esteem appears to be an essential ingredient for psychosocial well-being through the modulation of personal aspirations, goals, motives and social interactions (Lakey \& Scoboria, 2005). In individuals presenting health problems, it is associated with better adjustment, and less depression and helplessness (Gureje, Harvey, \& Herrman, 2004). Individuals who express high levels of self-esteem appear to possess both belief and expectancy regarding their own merits, abilities, strengths and competence (Baumeister, Bratslavsky, Finenauer, \& Vohs, 2001; Rose, Endo, Windschitl, \& Suls, 2008). Here, optimism provides as intrapersonal resource that may provide a 'buffering' effect against the impact of negative events thereby resulting in lower levels of depression, greater well-being, more health benefits and positive outcome as evidenced over a wide range of studies (e.g. Bjorck, Hopp, \& Jones, 1999; Scheier \& Carver, 1992; Taylor \& Brown, 1988).

The role of self-esteem in adolescent psychosocial development presents a vital component for health and quality of life (Goertzel \& Goertzel, 1991; Harter, 1990; Varni, Katz, Colegrove, \& Dolgin, 1994). In adolescents and young adults, low self-esteem is generally associated with depressiveness and anxiety, sexual risk-taking and substance abuse, as well as personality and mental problems (Izutsu, Tsutsumi, \& Matsumoto, 2009; Li, Chan, Chung, \& Chui, 2010; Rueger, Malecki, \& Demaray, 2010; Veselska et al., 2009). In the present study, the three major variables examined were Culture (Indonesian versus Swedish), Age (under 26 years versus over 26 years) and Affective states. Thus, the above studies, derived from Japan, North America, Hong Kong and the Slovak Republic, offer converging evidence regarding the influence of self-esteem upon both markers of health and personal profiles.

\subsection{Affective States}

Affective state may be considered as the expression of the concatenation of feelings and emotions stemming from the outcome of individuals' appraisals, evaluations and decisions of the situations and events the individuals are confronted with (Watson, Pennebaker, \& Folger, 1987). The final outcome of an individual's evaluation of the immediate social/physical/occupational environment may be expressed in various behavioural forms some of which may be suitable to the situation/event, others may give an impression of normality and still others may express behavioural disturbances, generally in the shape of affective disorders characterised by disorder feelings and emotions that produce, in consequence, a plethora of maladaptive and self-defeating functional, or rather dysfunctional, expressions. To some extent, these affective problems may be heritable, but for present purposes this review will focus exclusively upon the role of environmental, particularly cultural, influences in final common pathways of affect that individuals bring with them to daily events confronting them, and the suitability of coping measures available. Certainly, individual confrontation with stressful events remains a central issue. It is clear that in addition to adverse effects on well-being and quality-of-life, situations associated with stress, anxiety, fatigue and depression pose potentially grave dangers for health. Indicative of maladaptive affective profile, work-related stress has been associated with "burnout" and persistent fatigue syndrome (Palomo, Beninger, Kostrzewa, \& Archer, 2004).

Individuals' particular responses to negative events are directly generally by situation profiles consisting of the sum total of a complex array of personal characteristics, including intellectual and cognitive abilities, emotional feelings as reflected by the relationship between positive and negative effect, originality and flexibility in problem-solving, degree of social support and contacts, and willingness to take personal risks. Affect refers to subjective moods and feelings, rather than thoughts concerning specific events, and is intimately connected to feelings of depression, anxiety, fatigue, stress and 'burnout'. Applications of these notions of affect render an individual's experience of stress as highly subjective with coping expressions perceived as homeostatic/ 
transformational responses leading to either positive/negative outcome. Depressive or anxious predispositions are likely to affect the outcome of personal trait measurements. Thus, the two basic affective factors, PA and NA, have emerged as important dimensions of an individual's emotional experience. The PA-NA self-estimates of affect evoke expressions of mood and ongoing feelings thereby corresponding to measures of personality and emotionality but also providing a probability against which aspects of cognitive performance may be assessed (Bood, Archer \& Norlander, 2004; Norlander, Bood, \& Archer, 2002). Watson and co-workers (e.g. Watson et al., 1987) have demonstrated repeatedly that NA is associated with measures of neuroticism and negative emotionality, as well as marked symptoms of stress. Conversely, PA expresses enthusiasm, activity, alertness, control, commitment and challenge ('hardiness'), with a general disposition towards a positive outlook and a satisfactory perception and appraisal of potentially stressful events.

Both PA and NA influence the manner and extent to which individuals view, experience and approach stressful events over both time and circumstance. High NA is associated with subjective complaints, poor coping and trait anxiety (Karlsson \& Archer, 2007) whereas high PA is associated with sociability, control, helpful behaviour, feelings of duty, accuracy, care in decision-making and positive attitude over time and circumstance. Thus, high PA individuals experience a greater appreciation of life, more security, generally show more self-confidence, more social relations and assertiveness, greater satisfaction of friends, and are often described as passionate, happy, energetic and alert; high NA individuals experience the reverse, greater stress, strain and cynicism in a wide range of circumstances and events of which they experience slight, if any, control. Note that the contributions of positive upon expectancy motivation, cognitive functioning, clinical problem-solving, decision-making considerations, creative problem-solving, word associations and memory accessibility have all been documented, thereby underlining associations between affective state and cognitive processing (Norlander, von Schedvin, \& Archer, 2005).

Gross and John (2003) have presented the notion of emotional regulation according to which individuals differ in their use of emotion regulation strategies such as reappraisal and suppression, and these individual differences have implications for affect, well-being, and social relationships. Four general observations appear pertinent: (i) the habitual use of reappraisal and suppression, (ii) the relative influences of convergent and discriminant validity, (iii) the prevailing situation through which reappraisers experience and express greater positive emotion and lesser negative emotion, whereas suppressors experience and express lesser positive emotion, yet experience greater negative emotion, and finally (iv) the observation that reappraisal is associated with better interpersonal functioning, whereas using suppression is associated with worse interpersonal functioning, and that the employment of reappraisal is related positively to well-being, whereas using suppression is related negatively.

\subsection{Locus of Control}

Locus of control (Rotter, 1966) refers to a generalized expectancy of perceived internal or external control through which individuals associate events with their own behaviour or relatively permanent characteristics. Individuals assuming that event outcomes are due to their own ability, skills, efforts, and/or characteristics are referred to as possessing an Internal locus of control, whereas individuals assuming that event outcomes are due to external forces, such as luck, chance, fate and/or other powerful forces are referred to as possessing an External locus of control. According to the notion of locus of control, individuals may be characterised along a spectrum of "highly internal" or "highly external". It has been observed that individual status regarding locus of control at the start of rehabilitation, the greater the extent of internal locus of control exerted an important influence upon the probability of positive outcome of vocational rehabilitation programs. Those individuals expressing a predominantly external locus of control attaining a less favourable point of departure at the start of vocational rehabilitation as well as a less favourable outcome for health status, length of sick leave and duration of unemployment. Locus of control orientation (internal versus external) of small business owners-managers was related to efficacy of management strategies and leadership styles, as well as financial performance. 
Cultural influences upon health, affect, self-esteem and impulsiveness: An Indonesian-Swedish comparison

The purpose of the present investigation was to ascertain the cognitive-emotional profiles displayed through the assessment of self-reported affect, self-esteem, motivation, stress-energy balance, locus of control, optimism and impulsiveness as expressed by individuals from two quite different cultures: Indonesian and Swedish, and representing two comparable age groups: those under 26-years and those over 26-years. These individuals were taken from different occupations as represented by students and company employees.

\subsection{Hypothesized Cultural Aspects: Main Effects}

It has been assumed that citizens of a country are, more or less, homogeneous on the dimensions of individualism and collectivism, and also that individualism is highly regarded in Western societies, whereas collectivism is preferred in Asian societies. In a society characterized of individualism it is more desirable to reach individual goals than the goals of the group. In the collectivistic society the citizens are highly motivated by the group's norms, and willing to refrain from own personal desires in favour of the group (Hofstede, 1980; Hofstede \& Hofstede, 2005). Oichi and Diener (2001) found that individualistic people expressed positive emotions more often than collectivistic people due to independent goal pursuit (i.e., goal pursuit for fun and enjoyment) while collectivistic people performed interdependent goal pursuit (i.e., goal pursuit to please parent and friends).

Negative attributes of individuals' 'affective personal profile' appear to predispose them to confrontations with stressful situations from perspectives that differ considerably from individuals who report positive attributes. Combinations of PA and NA provide opportunities for the identification of cognitive-emotional pre-symptom profiles that underline individuals' pursuit of well-being (Archer, Adolfsson, \& Karlsson, 2008; Archer, Adrianson, Plancak, \& Karlsson, 2007; Nima, Archer, \& Garcia, 2012). Recent analyses have focused upon the issue of ethnicity and affective states (Arango-Lasprilla et al., 2009; Le, Lai, \& Wallen, 2009) as well as health status (Goza \& Ryabov, 2009; Saalfrank, Wang, \& Brown, 2009). It has been found that high levels of impulsive behavior are incompatible with positive affect and self-esteem but rather are associated with negative affect, external locus of control and amotivation (Archer, Kostrzewa, Palomo, \& Beninger, 2010; Archer, Oscar-Berman, Blum, \& Gold, 2012; Palomo, Beninger, Kostrzewa, \& Archer, 2008a, b).

Hypothesis 1: Negative effect, low level of impulsive behaviour and external locus of control, may be expected to a higher degree in a collectivistic society such as Indonesia compared to an individualistic society such as Sweden. There will also be main effects on age-groups in both cultures.

The general status of health is higher in Sweden than in Indonesia (Fischer \& Boer, 2011) and it may be expected that Indonesian participants will express a higher level of optimism than the Swedish participants due to the "postmodern paradox", implying that increased individualism and materialism are associated with an overall decline in well-being (Cushman, 1990). Suh, Diener, and Updegraff (cited in Diener, 2012) found that a person's moods and emotions were more predictive of life satisfaction in an individualistic culture; whereas a person's social life was more predictive of life satisfaction in a collectivistic culture. Individualistic societies permit individuals more freedom to decide on their own life course and demand fewer sacrifices for the group (Suh \& Koo, cited in Fischer \& Boer, 2011) compared to collectivistic societies. Proctor, Linley, and Maltby (2010) found that people with a higher score on happiness tend to have a lower score on depression, negative effect, and social stress. This result is in accordance with Mohammadi (2011) suggesting that negative affect is positively related to depression and anxiety, and positive affect is negatively related to depression and anxiety. The perception of stress is culturally different and according to research on culture and social support (Kim, Sherman, \& Taylor, 2008) it seems as Asians are less willing to seek support due to concern about disturbing social relationships (Hashimoto, Mojaverian, \& Kim, 2012).

Hypothesis 2: The Swedish group ought to report a higher self-reported health, but also a higher degree of stress and depression, and a lower degree of energy than the Indonesian group. There will also be main effects on age in both cultures. 
Cross-cultural surveys of subjective well-being have consistently shown that individuals who share an Eastern cultural heritage report less frequent positive affect and lower levels of life satisfaction than those sharing a Western cultural heritage (Diener, 2012). Wirtz, Chius, Diener and Oishi (2009) showed that individualistic people recalled positive effect, and took responsibility for positive events, more often than collectivistic people who were likely to attribute negative events to the self. Westerners rely on their feeling of self-esteem when evaluating their own life satisfaction, whereas Easterners depend on self-esteem as well as the presence of harmony in interpersonal relationships. It is also found that self-esteem is a better predictor of life satisfaction than relationship harmony in the United States whereas self-esteem and relationship harmony predicted life satisfaction equally well in Hong Kong. In individualistic cultures (such as the United States), self-confidence, independence, and the priority of the self, assume precedence over group harmony, resulting in higher levels of self-competence but lower levels of self-liking. In collectivistic cultures (such as China), the individual needs for self-confidence and efficacy are subordinated to the social needs of others, resulting in overall higher self-liking but lower self-competence (Schmitt \& Allik, 2005). The fast growing economy in Indonesia (Oberman, Dobbs, Budiman, Thompson, \& Rosse, 2012) may have an influence on general optimism towards the future and especially among young people, leading to a high level of self-esteem.

Hypothesis 3: The Indonesian participants may express a higher level of optimism and higher self-esteem than the Swedish participants, associated with a high level of PA and internal Locus of control. There will also be main effects on age in both cultures.

\section{Method}

\subsection{Participants}

105 Swedish respondents ( 83 women and 22 men) aged 19 to 55 years, filled in an on-line questionnaire and 240 Indonesian respondents ( 88 women, 141 men and 11 missing on gender), and aged 18 to 54 years, filled in a paper questionnaire. Median for age in both groups was 27 years $(s=8.5)$. Two age categories were derived from each respective cultural group: one younger group (age range 19 - 26 years) and one older group (age range $27-$ 55 years).

\subsection{Instruments}

The test-battery consisted of psychometric test instruments including Positive Affective and Negative Affect Scale, Stress and Energy, Dispositional optimism, Self-Esteem Scale, Hospital Anxiety and Depression, Impulsivity, and Locus of Control.

Positive affect (PA) and negative affect (NA) scale (PANAS). The PANAS-instrument provides a self-estimation of "affect", both positive and negative. It consists of 10 adjectives for the NA dimension and 10 adjectives for the PA dimension. The test manual postulates that the adjectives describe feelings (Affect) and mood level. Participants were instructed to estimate how they felt during the last few days. The response alternatives were presented on a five-grade scale that extended from where ' 1 ' = "not at all" to '5' = "very much". For each participant the responses to the 10 negatively-charged adjectives were summated to provide a total NA-result for NA affect, and similarly the responses to the positively-adjectives were summated to provide a total PA-result for PA affect. The PANAS instrument has been validated through studies analyzing conditions associated with general aspects of psychopathology, as well as a multitude of other expressions of affect. Previous studies have modified and developed the PANAS instrument further through a subject-response based derivation of the four types of affective personality. This procedure was implemented in the present study through dividing the results on the PA-scale into two parts thereby distributing the participants into one group with high PA and another group with low PA (cut-off point $=53.2 \%)$. The same procedure was implemented for the participants' responses on the NA-scale (cut-off point $=48.9 \%$ ). Following this, the results from these two 
Cultural influences upon health, affect, self-esteem and impulsiveness: An Indonesian-Swedish comparison

scales were combined according to the procedure that assigned each one of the participants into one of the four affective personality groups, as follows: individuals showing high PA and low NA ("Self-fulfilling"), high PA and high NA ("High affective"), low PA and low NA ("Low affective") and low PA and high NA ("Self-destructive").

Stress and energy (SE). The SE-instrument is a self-estimation scale, consisting of 12 items, that assesses individuals' experience of their own stress and energy. The test is divided into two sub-scales that express each participant's level of mood in the two dimensions: "experienced stress" and "experienced energy". Response alternatives are ordered within five-graded scales that extend from $1=$ "not at all" to $5=$ "very much". The instrument has been validated through studies concerning occupational burdens and pressures.

Hospital anxiety and depression (HAD). HAD provides a reliable and valid self-estimation instrument that assesses an individual's degree of anxiety and depression. The instrument consists of 12 statements, each followed by four response alternative from which the participant is instructed to mark the appropriate one. The alternatives include: "most often", "often", "now and then" and "not ever". Summated response values fewer than 6 are considered normal, values between 6 and 10 indicate a border level while values above 10 indicate a probable anxiety and/or depression diagnosis.

Barratt's impulsiveness scale (BIS). The present modified, Swedish version BIS-11 instrument is a self-estimation 25-item questionnaire that assesses impulsiveness (Patton et al., 1995), according to Swedish norms and has been applied to a series of studies with healthy volunteers (cf. Palomo et al., 2008a). Participants respond to statements on a 4-point scale, "Never" - "Sometimes" - "Often" - "Always", whereby 16 out of the 25 items express impulsiveness, such as "I do things without consideration", or "I act impulsively", and, conversely, 9 out of 16 items express non-impulsiveness, such as "I have good self-control", or "I plan for the future". Nine of the twenty-five items are scored formulated to express 'non-impulsiveness' thereby providing a reverse order, avoiding response bias, and sixteen items provided direct scores of impulsiveness. According to the factor analysis study by Li and Chen (2007), BIS items may be chosen to produce three factors, inability to plan, lack of self-control and sensation/novelty seeking that are tangential to the three subscales, nonplanning, motor and cognitive impulsiveness. BIS has been translated into several different languages with test-retest reliability ranging from 0.71 to 0.89 (Fossati, Di Ceglie, Acquarini \& Barratt, 2001; Someya et al., 2001).

Life orientation test (LOT). The LOT-instrument is a self-estimation instrument that assesses an individual's degree of dispositional optimism. The instrument is based on a general model, regarding self-regulated behaviour that indicates that optimism exerts meaningful behavioural consequences based on the model. It was constructed originally to study the extent to which the personality trait optimism was associated with the ability to develop suitable 'coping strategies' in connection with severe psychological and physical handicaps. The instrument consists of 12 statements from which each participant is instructed to assess the extent to which each of these statements fits in with him/her as an individual. The response alternatives are presented on a five-graded scale extending from '1' = "strongly disagree" to '5' = "strongly agree". LOT is a suitable scientific instrument with an estimated internal consistency of 0.76 (Cronbach's alpha) and a Test-Retest reliability of 0.79 (Pearson's $r$ ), indicating that the test result is stable over time. The LOT test requires about 5 minutes for completion.

Rosenberg self-esteem scale (SES). The SES instrument is a self-estimation, 10-item questionnaire which has been constructed to measure the extent to which individuals' consider themselves "sufficiently functional", particularly in adolescents and young adults (Rosenberg, 1965). Self-esteem is measured using ten items (statements, each item rated on a four point Likert scale) concerned with feelings about oneself and one's attitude towards one's resources, relations to others and achievements, whereby half of the statements express positive aspects about self and half express negative aspects. The participants were required to respond with the number that they considered to fit the degree to which they agreed with the statement or disagreed with the statement, whereby 1 = "agree completely" and 4 = "disagree completely". For example, statements like "I can do things as 
Adrianson, L., Ancok, D., Ramdhani, N., \& Archer, T.

well as anybody else", or "I wish that I had more respect for myself", or "On the whole I am satisfied with myself" were included.

Locus of Control (LoC). Locus of Control was measured using a modified version of the Rotter (1966) scale. The scale has a minimum score of 8 and a maximum of 40 , with a lower score representing an external locus of control orientation and a higher score representing an internal locus of control orientation. Several empirical studies have shown that perceived control is strongly correlated with rehabilitational outcomes, not least empowerment.

\subsection{Procedure}

The Swedish questionnaire was distributed on-line (e-val) among students in six classes (495 students) at University of Boras. All instructions and questionnaires were in Swedish and the participants were guaranteed anonymity. The background variables were sex, age, education, parents' occupation, parents' education, number of siblings, social-economic belonging, and health in general. The Indonesian language questionnaire was distributed to 122 individuals within a private company (National Gas Company) and 118 students at the Gadjah Mada University (Behavior Modification and Cross Cultural Psychology). The company executives themselves decided upon a representative selection of participants and the university students were all from different courses within the social sciences. Background variables were parents' occupation, if the respondent owned a motorcycle, and if the respondent owned a car. The latter is a measure of economical belonging. The Indonesian questionnaire was translated from English to Bahasa Indonesia, and then back to English again. The Swedish questionnaire was only translated from English to Swedish.

\section{Results}

The participants were instructed to respond to the background question: "How do experience your own general level of health?" on a 5-grade scale varying from "very bad" to "very good", with higher values indicating higher levels of health. Table 1 presents the means and SD for Swedish and Indonesian participants within the younger and older age groups.

\section{Table 1}

Self-reported health among Swedish and Indonesian participants

\begin{tabular}{llll}
\hline Age & $<27$ years & $>27$ years & Total \\
\hline & & (Means \pm SD) & \\
\hline Swedish & $4.16 \pm .84$ & $3.92 \pm .98$ & $4.06 \pm .92$ \\
Indonesian & $3.64 \pm .74$ & $3.87 \pm .78$ & $3.75 \pm .77$ \\
\hline
\end{tabular}

The Swedish respondents reported a somewhat better health than the Indonesian respondents. There was a small non-significant difference between the age-groups in Sweden, showing that the younger respondents had a better health than the elder. This pattern was reversed among the Indonesian participants; the elder reported significantly higher level of health than the younger, $t=-2.31, p=.021$. There was also a difference between the sexes in the Indonesian group, $t=2.48, p=.014$, showing that men $(M=3.85, s=.79)$ were more healthy than women $(M=3.59, s=.74)$. There was no difference among the Swedish participants with regard to sex $(M$ men=4.18, s=.66, $M$ women=4.02, s=.97). Cultural influences upon several aspects were observed between the Indonesian and Swedish participants and age-category differences were forthcoming (i.e. $<26$ years vs $>26$ years) as a function of culture. Table 2 presents results on two-way ANOVAs on culture and age, Cronbach's alpha values, and means and standard deviations within each culture and each age-group, respectively.

The alpha-values for PA and NA, Stress, Anxiety, Positive and Negative Self-esteem, and Impulsivity indicate acceptable levels of reliability whereas Optimism and HAD Depression show rather low alpha-values (0.59 and 0.63, respectively) as well as internal (0.68) and external LoC (0.62). First, results from two-way ANOVAS are presented with culture and age-category as independent variables and Positive Affective (PA) and 
Cultural influences upon health, affect, self-esteem and impulsiveness: An Indonesian-Swedish comparison

Negative Affect (NA), Stress, Energy quotient, Depression and Anxiety, Impulsivity, Optimism, Self-Esteem, and Internal-External Locus of Control as dependent variables (between-group differences), and second differences between the age-groups within the two cultures (within-group differences).

Table 2

Two-way ANOVA results

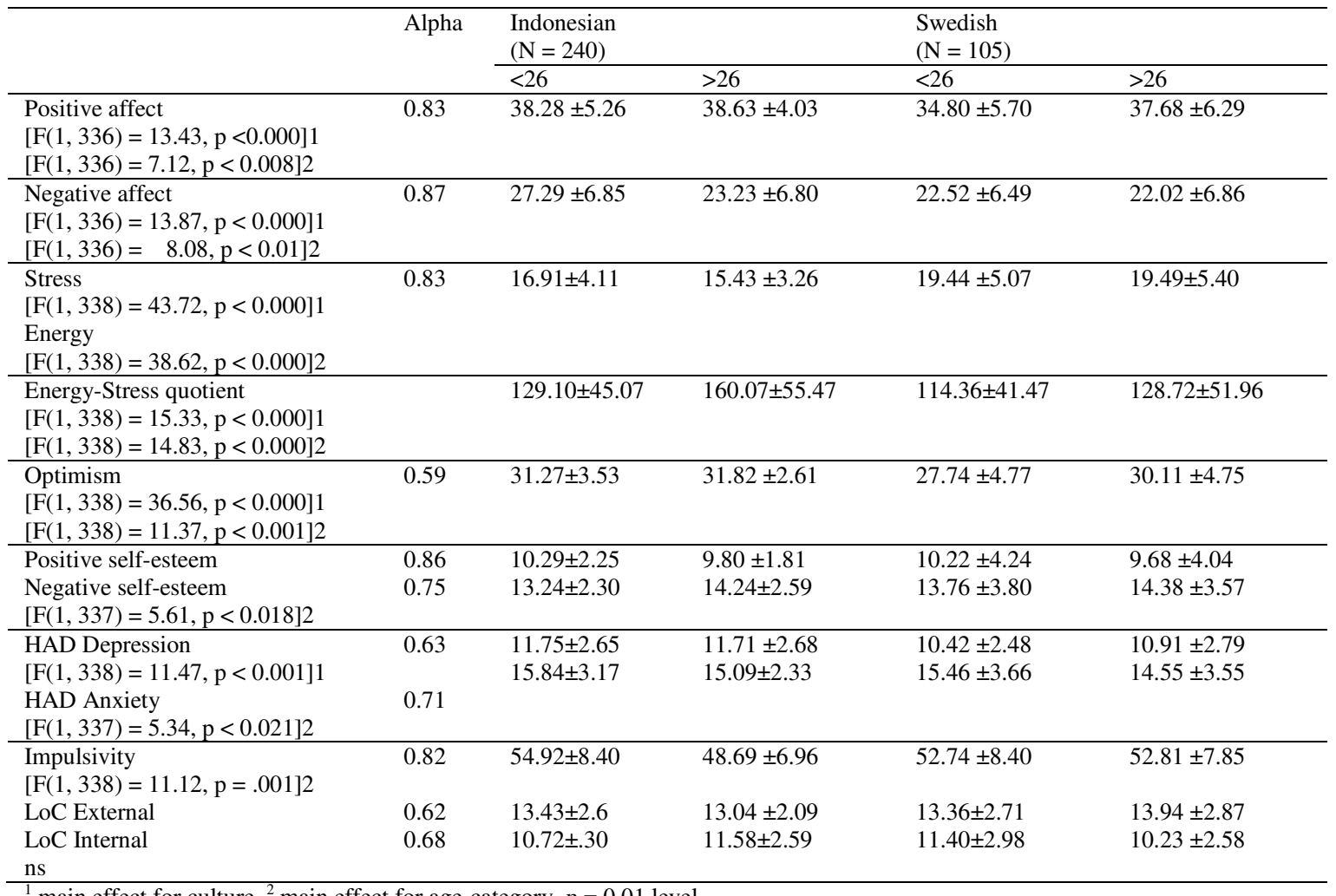

${ }^{1}$ main effect for culture, ${ }^{2}$ main effect for age-category, $p=0.01$ level

Hypothesis 1. It was assumed that Negative effect, low level of Impulsive behaviour and External Locus of Control would be shown to a higher degree in a collectivistic society such as Indonesia compared to an individualistic society such as Sweden.

Between group differences (see Table 2 for F-values). There was a significant main effect on culture with regard to Negative Affect, whereby Indonesian participants expressed more NA $(M=25.26, s=.45)$ compared to the Swedish participants $(M=22.27, s=.70)$. There was also a main difference on age-groups showing that younger respondents expressed a higher degree of NA than elder respondents. There was no culture difference with regard to Impulsiveness but there was an age-group difference, young respondents $(M=53.83, s=.67)$ reported more impulsive behaviour than elder respondents $(M=50.75, s=.64)$.

Within group differences (see Table 2 for group values). Among the Indonesian participants, the under 26-years group expressed a higher level of NA than the over 26-years group, $t=4.54, p=.000$, df $=231$.The former also expressed a higher level of Impulsiveness than the over 26-years group, $t=6.22, p=.000, \mathrm{df}=233$. There was no age difference on External LoC in the Indonesian group and no age differences in the Swedish group on Negative Affect, Impulsivity, or External LoC, respectively.

Hypothesis 2: The Swedish group ought to report a higher self-reported Health, but also a higher degree of Stress and Depression, and lower degree of Energy than the Indonesian group.

Between group differences (see Table 2 for F-values). The responses of Swedish and Indonesian participants indicate that the former report their Health to be somewhat better than the latter (see Table 1), 
$F(1,336)=8.88, p=.003$. There was no main effect on age-group but indication of a group effect for culture, $F(1,336)=5.92, p=.015$; Indonesian participants over 26 years reported better Health than participants younger than 27 whereas the Swedish group younger than 26 reported better Health than the elder group. There was a main effect for culture in relation to Stress, showing that the Swedish respondents ( $M=19.47, s=.42)$ were more stressed than the Indonesian respondents $(M=1617, s=.28)$. On the other hand, the Indonesian group reported a higher degree of Depression $(M=11.73, s=.17)$ than the Swedish group $(M=10.66, s=.26)$. There was no difference with regard to age-groups. The Energy/Stress Quotient showed that the Indonesian group expressed higher levels of Energy-Stress quotient $(M=144.59, s=3.25)$ than the Swedish group $(M=121.54, s$ $=4.91)$. There was no main effect on culture with regard to Energy, but the younger respondents in both groups showed less Energy $(M=121.73, s=4.24)$ than the elder groups $(M=144.40, s=4.08)$.

Within group differences (see Table 2 for group values). Among the Indonesian participants, the under 26-years group expressed a lower degree of Health than the over 26-years group, $t=-2.3, p=.021$, $\mathrm{df}=231$, and they also reported more Stress than elder, $t=3.07, p=.02, \mathrm{df}=233$. This is in accordance with the result that the elder respondents also reported a higher degree of Energy than the younger, $t=7.15, p=.000, \mathrm{df}=233$, as well as a higher level of Energy-Stress quotient showed the same result, $t=-4.66, p=.000, \mathrm{df}=233$. There was only one age-group difference in the Swedish group; respondents over 26 years reported a higher degree of Energy than the younger respondents, $t=2.66, p=.009, \mathrm{df}=101$.

Hypothesis 3: The Indonesian participants may express a higher level of Optimism and higher Self-esteem than the Swedish participants, associated with a high level of Positive Affect and Internal Locus of Control.

Between group differences (see Table 2 for F-values). There was a culture difference whereby the Indonesian participants $(M=31.54, s=.23)$ expressed greater Optimism than the Swedish participants $(M=$ 28.93, $s=.36)$. The older respondents in both cultures showed a higher degree of Optimism ( $\mathrm{M}=29.51, \mathrm{~s}=.31)$ than the younger respondents $(M=30.97, s=.30)$.There was no main difference between cultures on Positive or Negative Self-esteem. Both Indonesian and Swedish participants showed an age difference in Negative Self-esteem, the under 26-years group $(M=13.50, s=.25)$ expressed a lower level of Negative Self-esteem than the over 26-years group $(M=14.31, s=.24)$. There were significant differences between the cultures with regard to Positive Affect, whereby Indonesian participants expressed more PA $(M=38.44, s=.34)$ compared with Swedish participants $(M=36.24, s=.50)$. Elder respondents in both groups showed a higher degree of PA $(M=$ $38.15, s=.42)$ than younger $(M=36.54, s=.44)$. There was no main effect on Internal Locus of Control.

Within group differences (see Table 2 for group values). There was only one age-group difference among the Indonesian respondents; the elder respondents had a higher level of Internal LoC than the younger, $t=-2.37$, $p=.018, \mathrm{df}=233$. Among Swedish participates, the over 26-years group had a higher level of PA than the younger, $t=-2.4, p=.017, \mathrm{df}=101$.

\subsection{Affective States}

There were differences both between and within cultures with regard to PA and NA and it could therefore be of interest to analyze the four different types of affective states (high affect, low affect, self-fulfilling, self-destructive) as independent variables and Health, Stress, Energy and Stress-Energy quotient, Optimism, Negative Self-Esteem, Depression and Anxiety, and Impulsivity as dependent variables. Table 3 presents results on two-way ANOVAs on culture and affective states as well as means and standard deviations within each culture and affective state, respectively.

First, results from two-way ANOVAS are presented with culture and affective state as independent variables and Health, Stress, Energy and Energy quotient, Optimism, Negative Self-Esteem, Depression and Anxiety and Impulsivity as dependent variables. Second, differences within the two cultures are presented. Only self-fulfilled and self-destructive states will be reported. 
Cultural influences upon health, affect, self-esteem and impulsiveness: An Indonesian-Swedish comparison

Table 3

Two-way ANOVA results

\begin{tabular}{|c|c|c|c|c|c|c|c|c|}
\hline & $\begin{array}{l}\text { Indonesian } \\
(\mathrm{N}=240)\end{array}$ & & & & $\begin{array}{l}\text { Swedish } \\
(\mathrm{N}=10\end{array}$ & & & \\
\hline & High Affect & $\begin{array}{l}\text { Low } \\
\text { Affect }\end{array}$ & Destructive & Fulfilled & $\begin{array}{l}\text { High } \\
\text { Affect }\end{array}$ & $\begin{array}{l}\text { Low } \\
\text { Affect }\end{array}$ & Destructive & Fulfilled \\
\hline $\begin{array}{l}\text { Health } \\
{[\mathrm{F}(3,341)=14.14, \mathrm{p}<} \\
0.000]\end{array}$ & $3.72 \pm .70$ & $3.76 \pm .48$ & $3.36 \pm .57$ & $\begin{array}{l}4.21 \\
\pm .96\end{array}$ & $\begin{array}{r}4.20 \\
\pm .84\end{array}$ & $3.96 \pm .90$ & $3.68 \pm .76$ & $4.41 \pm 1.02$ \\
\hline $\begin{array}{l}\text { Stress } \\
{[\mathrm{F}(3,343)=29.98, \mathrm{p}} \\
<0.000] \\
\text { Energy } \\
{[\mathrm{F}(3,343)=39.75, \mathrm{p}} \\
<0.000]\end{array}$ & $\begin{array}{l}16.60 \pm 3.05 \\
21.69 \\
\pm 2.23\end{array}$ & $\begin{array}{l}15.96 \\
\pm 3.12 \\
21.70 \\
\pm 3.26\end{array}$ & $\begin{array}{l}18.10 \pm 3.77 \\
19.34 \\
\pm 2.91\end{array}$ & $\begin{array}{l}13.51 \pm 3.06 \\
24.71 \\
\pm 2.93\end{array}$ & $\begin{array}{l}20.45 \\
\pm 5.21 \\
22.10 \\
\pm 3.28\end{array}$ & $\begin{array}{l}17.59 \\
\pm 4.82 \\
20.44 \\
\pm 4.28\end{array}$ & $\begin{array}{l}22.83 \pm 4.04 \\
19.38 \pm 3.04\end{array}$ & $\begin{array}{l}16.59 \pm 4.85 \\
24.34 \pm 317\end{array}$ \\
\hline $\begin{array}{l}\text { Energy-Stress } \\
\text { quotient } \\
{[\mathrm{F}(1,343)=42.81, \mathrm{p}} \\
<0.000]\end{array}$ & $\begin{array}{l}136.09 \\
\pm 32.86\end{array}$ & $\begin{array}{l}141.65 \\
\pm 35.47\end{array}$ & $\begin{array}{l}112.76 \\
\pm 32.00\end{array}$ & $\begin{array}{l}194.74 \\
\pm 62.17\end{array}$ & $\begin{array}{l}119.63 \\
\pm 46.30\end{array}$ & $\begin{array}{l}126.85 \\
\pm 46.45\end{array}$ & $\begin{array}{l}89.06 \\
\pm 21.22\end{array}$ & $\begin{array}{l}158.45 \pm 50 \\
73\end{array}$ \\
\hline $\begin{array}{l}\text { Optimism } \\
{[\mathrm{F}(3,343)=31.39, \mathrm{p}<} \\
0.002]\end{array}$ & $31.62 \pm 2.53$ & $\begin{array}{l}31.60 \\
\pm 2.74\end{array}$ & $29.84 \pm 3.41$ & $33.35 \pm 2.36$ & $\begin{array}{l}31.10 \\
\pm 4.28\end{array}$ & $\begin{array}{l}29.30 \\
\pm 4.77\end{array}$ & $25.14 \pm 3.64$ & $31.24 \pm 4.18$ \\
\hline $\begin{array}{l}\text { Negative } \\
\text { Self-esteem } \\
{[\mathrm{F}(3,341)=12.47, \mathrm{p}<} \\
0.000]\end{array}$ & $13.22 \pm 1.59$ & $\begin{array}{l}14.60 \\
\pm 2.23\end{array}$ & $12.06 \pm 2.13$ & $15.38 \pm 2.54$ & $\begin{array}{l}14.45 \\
\pm 2.98\end{array}$ & $\begin{array}{l}14.07 \\
\pm 3.96\end{array}$ & $13.17 \pm 2.71$ & $14.97 \pm 4.54$ \\
\hline $\begin{array}{l}\text { Depression } \\
{[\mathrm{F}(3,342)=10.32, \mathrm{p}<} \\
0.000] \\
\text { Anxiety int } \\
{[\mathrm{F}(3,343)=22.90, \mathrm{p}<} \\
0.000]\end{array}$ & $\begin{array}{l}12.48 \pm 2.81 \\
13.65 \pm 2.27\end{array}$ & $\begin{array}{l}11.22 \\
\pm 1.88 \\
15.54 \\
\pm 2.38\end{array}$ & $\begin{array}{l}12.67 \pm 2.67 \\
16.57 \pm 3.39\end{array}$ & $\begin{array}{l}9.59 \pm 2.11 \\
13.65 \pm 2.27\end{array}$ & $\begin{array}{l}10.40 \\
\pm 2.60 \\
3.08 \\
\pm .69\end{array}$ & $\begin{array}{l}10.70 \\
\pm 2.66 \\
2.86 \pm .55\end{array}$ & $\begin{array}{l}11.97 \pm 2.71 \\
3.66 \pm .68\end{array}$ & $\begin{array}{l}9.44 \pm 2.11 \\
3.25 \pm .60\end{array}$ \\
\hline $\begin{array}{l}\text { Impulsivity } \\
{[\mathrm{F}(3,314)=11.35, \mathrm{p}<} \\
0.000]\end{array}$ & $53.47 \pm 8.13$ & $\begin{array}{l}53.14 \\
\pm 6.27\end{array}$ & $54.60 \pm 8.25$ & $45.65 \pm 6.21$ & $\begin{array}{l}52.05 \\
\pm 9.84\end{array}$ & $\begin{array}{l}52.15 \\
\pm 7.79\end{array}$ & $55.69 \pm 6.49$ & $51.00 \pm 7.82$ \\
\hline
\end{tabular}

Note. Main effect for affective state $p=0.01$ level

Between group differences (see Table 3 for F-values). The respondents in both cultures that reported their affect as self-fulfilling also reported better Health $(M=4.13, s=.09)$ than self-destructive respondents who reported the lowest value $(M=3.53, s=.09)$. The former also were Stressed to a lower level $(M=15.05, s=.42)$ than self-destructive respondents $(M=20.47, s=.42)$. Their Energy level was the highest given $(M=24.50, s$ $=.34)$ and the self-destructive the lowest value given $(M=19.36, s=.34)$ and the same pattern showed in the Energy-Stress quotient, $M=176.60, s=4.89$ and $M=100.91, s=4.75$, respectively.

Respondents with fulfilled affect state showed a higher degree of Optimism $(M=32.30, s=.37)$ than the self-destructive respondents $(M=27.49, s=.37)$. There was also an interaction effect between culture and affective states in Optimism, $F(3,343)=4.89, p=.002$. A post-hoc analysis with Bonferroni on culture and affective states for each culture showed that the mean differences were larger between the self-destructive and self-fulfilling (-6.10) states and self-fulfilling and high affective (-5.96) states in the Swedish culture compared to the Indonesian culture ( -3.51 and -1.79 , respectively), meaning that the differences in Optimism between the affective states were smaller among the Indonesian respondents.

The Negative Self-esteem was higher in the self-fulfilled group $(M=15.17, s=.30)$ than in the self-destructive group $(M=12.62, s=.30)$ but Depression $(M=10.09, s=.28$ and $M=12.32, s=.28$, respectively) and Anxiety $(M=13.55, s=.31$ and $M=16.99, s=.31$, respectively) were lower. There was also an interaction effect between culture and affective states in Anxiety, $F(3,343)=3.77, p=.011)$. A post-hoc analysis with Bonferroni for each culture showed that the differences was due to the self-fulfilling state respondents that differed from self-destructive (mean difference -2.92) and high affective respondents (mean difference -2.30) in the Indonesian group. In the Swedish group it was the self-destructive group that differed from the low affective (mean difference 4.04) and self-fulfilling (mean difference 3.97).

Impulsivity was lower in the self-fulfilled state $(M=48.32, s=.85)$ compared to the self-destructive state 
Adrianson, L., Ancok, D., Ramdhani, N., \& Archer, T.

$(M=55.14, \mathrm{~s}=.84)$. There was also an interaction effect between culture and affective states in Impulsivity $F(3,342)=3.11, p=.026)$. A post-hoc analysis with Bonferroni on culture and Impulsivity for each culture showed that the difference was due to the self-fulfilling state respondents among the Indonesians that differed from the self-destructive state (mean difference -8.95) and high affective state (mean difference -7.82). There were no differences in the Swedish group.

\subsection{Results of regression analyses}

In order to assess the extent to which Positive Affect, Negative Affect, Optimism, Anxiety and Depression, Impulsiveness, Positive and Negative Self-esteem and Health, respectively (dependent variables), may be predicted from the result outcome pertaining to the variables estimated in positive effect, negative effect, dispositional optimism, HAD anxiety and depression, impulsiveness, self-esteem, internal and locus of control and Health (with exclusion of dependent variable) as independent (predictor) variables. Table 4 presents the standardized weights from the multiple regression analyses with positive affect (Table 4a), negative affect (Table 4b), Optimism (Table 4c), HAD anxiety and depression (Table 4d), Impulsiveness (Table 4e), Self-esteem (Table 4f) and Health (Table 4g).

\section{Table 4}

Standardized weights from linear regression analysis

Note. a) Positive Affect $\left[\mathrm{F}_{(8,340)}=19.55, \mathrm{p}=.000\right.$; Adjusted $\left.\mathrm{R}_{2}=0.31\right]$, b) Negative Affect $\left[\mathrm{F}_{(8,338)}=34.2, \mathrm{p}=.000\right.$; Adjusted $\left.\mathrm{R}_{2}=0.44\right]$, c) Dispositional Optimism $\left[\mathrm{F}_{(8,338)}=25.36\right.$, $\mathrm{p}=.000$; Adjusted $\left.\mathrm{R}_{2}=0.37\right]$, d) HAD Anxiety and Depression $\left[\mathrm{F}_{(8,338)}=33.71, \mathrm{p}=.000 ;\right.$ Adjusted $\left.\mathrm{R}_{2}=0.44\right]$, e) $B I S\left[\mathrm{~F}_{(8.338)}=16.02, \mathrm{p}=.000 ;\right.$ Adjusted $\left.\mathrm{R}_{2}=0.26\right], f$ ) Self-esteem $\left[\mathrm{F}_{(8,338)}=5.21, \mathrm{p}=.000 ;\right.$ Adjusted $\left.\mathrm{R}_{2}=0.78\right]$, and $\mathrm{g}$ ) Health $\left[\mathrm{F}_{(8,338)}=13.48, \mathrm{p}=.000 ;\right.$ Adjusted $\left.\mathrm{R}_{2}=0.23\right]$, respectively, as Dependent Variables and Internal Locus, External Locus, Positive and Negative Affect, Dispositional Optimism, HAD Anxiety and Depression, Impulsiveness, Self-esteem and Health as Independent Variables, Predictor and Standardized $\beta$

a) Positive Affect

\begin{tabular}{lc}
\hline Predictor Variable & Standardized $\beta$ \\
\hline Dispositional Optimism & $0.41^{* *}$ \\
Health & $0.22^{* *}$ \\
Internal LoC & $-0.10^{*}$
\end{tabular}

Note. $* p=0.05 * * \mathrm{p}=0.01$, Predictor Variables: negative effect, external LoC, HAD, BIS and SES were non-significant

b) Negative affect

\begin{tabular}{ll}
\hline \multicolumn{2}{l}{ Predictor variable Standardized $\beta$} \\
\hline HAD & $0.43^{* *}$ \\
Impulsiveness & $0.13^{* *}$ \\
SES & $-0.12^{* *}$ \\
Health & $-0.21^{* *}$
\end{tabular}

Note. $* p=0.05 * * p=0.01$, Predictor variable: positive effect, internal LoC, external LoC and LOT were non-significant

c) Dispositional optimism

\begin{tabular}{ll}
\hline \multicolumn{2}{l}{ Predictor variable Standardized $\beta$} \\
\hline Positive affect & $0.37 * *$ \\
External LoC & $0.13 * *$ \\
HAD & $0.20 * *$ \\
Impulsiveness & $-0.18 * *$
\end{tabular}

Note. ${ }^{*} p=0.05 * * p=0.01$, Predictor variables: negative effect, internal LoC, SES and health were non-significant 
d) HAD

\begin{tabular}{ll}
\hline Predictor variableStandardized $\beta$ \\
\hline Negative affect & $0.43^{* *}$ \\
Impulsiveness & $0.14^{* *}$ \\
External LoC & $-0.10^{*}$ \\
Dispositional optimism & $-0.18^{* *}$
\end{tabular}

Note. $* p=0.05 * * p=0.01$, Predictor variable: positive effect, internal LoC, SES and health were non-significant

e) Impulsiveness (BIS)

Predictor variableStandardized $\beta$

\begin{tabular}{ll}
\hline Negative affect & $0.17 * *$ \\
Dispositional optimism & $-0.21 * *$ \\
HAD & $-0.19 * *$
\end{tabular}

Note. $* p=0.05 * * p=0.01$, Predictor variable: positive effect, internal LoC, external LoC, SES and health were non-significant

f) Self-esteem

\begin{tabular}{ll}
\hline \multicolumn{2}{l}{ Predictor variableStandardized $\beta$} \\
\hline Internal locus & $0.15^{* *}$ \\
External locus & $0.16^{* *}$ \\
Health & $0.11^{*}$ \\
NA & $-0.19^{* *}$
\end{tabular}

Note. ${ }^{*} p=0.05 * * p=0.01$, Predictor variables: positive effect, LOT, HAD and BIS were non-significant

g) Health

\begin{tabular}{ll}
\hline Predictor variableStandardized $\beta$ \\
\hline Positive affect & $0.24 * *$ \\
SES & $0.10^{*}$ \\
Negative affect & $-0.29 * *$
\end{tabular}

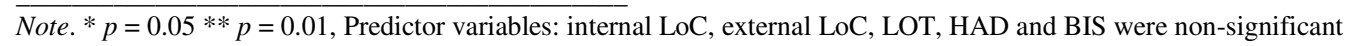

Regression analysis indicated that:

Note. PA $\left(F(8,340)=19.55, p=.00\right.$; Adjusted $\left.\mathrm{R}_{2}=0.31\right)$ was predicted by dispositional optimism and health and counter-predicted by Internal LoC, whereas NA $\left(F(8,338)=34.2, p=.00\right.$; Adjusted $\left.\mathrm{R}_{2}=0.44\right)$ was predicted by HAD and impulsiveness and counter-predicted by health and SES. Dispositional optimism $(F(8,338)=25.36, p$ $=.00$; Adjusted $\mathrm{R}_{2}=0.37$ ) was predicted by PA, External LoC and HAD and counter-predicted by impulsiveness. HAD- anxiety and HAD-depression $\left(F(8,338)=33.71, p=.00\right.$; Adjusted $\mathrm{R}_{2}=0.44$ ) were predicted by NA and impulsiveness and counter-predicted by external LoC and dispositional optimism. Impulsiveness $(F(8,338)=$ 16.02, $p=.00$; Adjusted $\mathrm{R}_{2}=0.26$ ) was predicted by NA and counter-predicted by dispositional optimism and HAD. Self-esteem $\left(F(8,338)=5.21, p=.00\right.$; Adjusted $\left.\mathrm{R}_{2}=0.78\right)$ was predicted by internal LoC, external LoC and health and counter-predicted by NA. Health $\left(F(8,338)=13.48, p=.00\right.$; Adjusted $\left.\mathrm{R}_{2}=0.23\right)$ was predicted by PA and SES and counter predicted by NA.

A second analysis was performed for each culture separately in order to assess the extent to which the affective states (HA, LA, SD, SF) as dependent variables may be predicted from health, stress, depression, dispositional optimism, self-esteem, impulsiveness, and external locus of control as independent (predictor) variables. 
Adrianson, L., Ancok, D., Ramdhani, N., \& Archer, T.

Table 5

Predictors of affective state

\begin{tabular}{llll}
\hline Affective State & & & \\
\hline Indonesia & & Sweden & \\
\hline Predictor Variable & Standardized $\beta$ & Predictor Variable & Standardized $\beta$ \\
\hline Health & $0.23^{* *}$ & Optimism & $0.33^{* *}$ \\
Optimism & $0.23^{* *}$ & Stress & $-0.19^{*}$ \\
SES & $0.14^{*}$ & Stress & $-0.23^{* *}$ \\
Adjusted $\mathrm{R}^{2}$ & 0.32 & & 0.23 \\
$F$ & 16.61 & & 5.3 \\
$\mathrm{df}$ & 7 & & 7 \\
$\mathrm{~N}$ & 232 & & 104 \\
\hline Note. & $* 0.05^{* *} \mathrm{p}=0.01$ & &
\end{tabular}

Predictor Variables Depression, Impulsiveness and External LoC were non-significant in the Indonesian group, and Health, Depression, Self-esteem, Impulsiveness and Extern LoC were non-significant in the Swedish group. Regression analysis indicates that Affective state, $F(7,233)=16.61, p=.00$; Adjusted $\mathrm{R}_{2}=0.32$, was predicted by health, optimism and SES and counter predicted by stress for the Indonesian group. The analysis for the Swedish group shows that Affective state, $F(7,104)=5.3, p=.00$; Adjusted $\mathrm{R}_{2}=0.23$, was predicted by optimism and counter predicted by stress for the Swedish group.

\section{Discussion}

The present study compared individuals from Indonesian culture with individuals from Swedish culture in two age-groups; respondents under 26 years and respondents over 26 years. The comparisons were analysed with regard to variables including estimations of health, stress and energy, anxiety and depression, positive and negative effect, optimism, positive and negative self-esteem, impulsiveness, and internal and external locus of control. The results may be summarised as follows:

a. Indonesian participants expressed, in accordance with the expectations, both more positive affect and more negative affect than Swedish participants, and less stress and a higher energy-stress quotient than the Swedish group. Additionally, the former expressed a higher level of optimism (expectation confirmed), but also more depression, against the expectation.

b. Both groups under 26-year expressed higher level of negative affect than the group over 26 years, whereas the groups over 26-year expressed a higher level of positive affect. The over 26-years age group in the Indonesian culture expressed better health and higher energy-stress quotient than the younger group. The under 26-years group in the Swedish culture showed better health than the elder group, and the latter also reported a higher energy-stress quotient. The under 26-years group expressed less optimism than the elder, while the elder groups showed more negative self-esteem than the younger groups. There were different age patterns in the two age-, and culture groups with regard to anxiety and impulsivity; the younger Indonesian group reported more anxiety and more impulsive behaviour than the elder while the elder group in Sweden showed more anxiety and impulsive behaviour than the younger group. Regression analyses, performed over all the participants, indicated that positive affect was predicted by dispositional optimism and health, whereas negative affect was predicted by anxiety - depression (HAD) and impulsiveness. Dispositional optimism was predicted by positive effect, external LoC and anxiety -depression. HAD anxiety and depression was predicted by negative affect and impulsiveness, whereas impulsiveness was predicted by negative effect. Self-esteem was predicted by internal/external LoC and health and, finally, health was predicted by positive affect and self-esteem.

The presence of cultural differences as expressed in the self-report analyses of Indonesian and Swedish individuals may reflect several differences between the two ethnic. It possible that Indonesia and Swedish people experience their relative life-situations quite differently, with the former expressing greater NA and the latter 
more stress and less energy, thereby reflecting the current socio-cultural differences between a country under rural and post-modern electronics industrial development (Indonesia) and one which has progressed through social upheavals of the industrial and IT-electronics age to the media-dependent society (Sweden) defining Western European circumstances. Indonesian individuals expressed greater optimism than Swedish individuals which reinforce the notion that culture aspects in the lives of the former may be preserved to a greater extent than the prevailing "generalized western european-anglosaxon culture" that offers a more diffuse self-identity to individuals.

Cultural ethnicity affects the psychosocial aspects of personal attributes in individuals, particularly under conditions of health provocation. For example, African Americans expressed poorer self-reported life satisfaction than Caucasians and Asians one year following traumatic brain injury. This observation was found not to be due to the pre-injury marital or employment status, cause of injury, nor injury severity or functional status of the individuals participating. The extent to which emotional suppression may generate socioaffective consequences has been considered (Butler et al., 2003; Gross \& John, 2003). Butler, Lee, and Gross (2007) have argued that from a cultural perspective these consequences may be moderated by cultural values. They tested this hypothesis in a two-part study, and found that, for Americans holding Western-European values, habitual suppression was associated with self-protective goals and negative emotion. In addition, experimentally elicited suppression resulted in reduced interpersonal responsiveness during face-to-face interaction, along with negative partner-perceptions and hostile behavior. It was observed that the deleterious effects were reduced when individuals with more Asian values suppressed, and these reductions were mediated by cultural differences in the responsiveness of the suppressors, suggesting that many of suppression's negative social impacts may be moderated by cultural values. This results is supported by Indonesian culture since in the collectivist culture like Indonesia, people are required by social norms to control their emotional expression. It is not appreciated to be impulsive. Refraining from expressing emotion makes the Indonesian subjects experience higher level of depression and anxiety (Carson et al., 2007; Mann, 1997; Troisi \& D'Argenio, 2004).

The present findings confirm previous observations from several aspects:(a) impulsiveness was predicted by high levels of NA (cf. Palomo et al., 2008b), (b) HAD was predicted by negative affect (cf. Archer et al., 2008), (c) self-esteem was counter-predicted by NA (cf. Archer et al., 2008), (d) PA was predicted by optimism (cf. Archer et al., 2008), and (e) NA was predicted by HAD (cf. Archer et al., 2008). Self-reported estimation of one's own health was predicted by PA and counter-predicted by NA. This observation confirms the results of several other studies that included self-report measures of PANAS combined with questionnaires assessing coping resources, work stress, and health inventories (e.g. Andersson-Arntén, Jansson, \& Archer, 2008; Bood et al., 2004). In view of the cultural diversity which was the major variable of the present study, the robustness of the data obtained from the regression analyses appears to be more than adequate. The separate analyses showed that affective state was predicted by health, optimism and self-esteem and counter predicted by stress in the Indonesian group. Affective state was predicted by optimism and counter predicted by stress in the Swedish group.

Indonesian is considered by Hofstede and Hofstede (2005) as having collectivistic culture, and people of collectivistic cultures focus more on relationship with others that is based more on feeling/emotion than on ratio. Indonesians are more sensitive in reacting toward something that is related to emotion, both positive and negative emotions. This may be a reason why Indonesian showed higher both PA and NA. In a collective culture as Indonesia people tend to be more optimistic, have higher energy and experience less stressful feelings since they see other people as part of their own life. People care about each other, so if there is a personal problem in their life they can share it with others. This sharing will reduce their stress and make them more optimistic.

Simultaneously, the Indonesian respondents showed a higher depression level and one explanation can be the social problems that are experienced by the Indonesian people today. There are more and more communal conflicts, more homicide and rape cases that are shown on TV and reported in the newspaper. Government shows less care toward the poor groups even though Indonesia as a country experiences a high economic growth. 
Politicians are involved in corruption; they do not purely fight for the need of people but only think about their own needs. Law and justice are not for the poor but for those who have power and money.

The study confirmed also the presence of age-group differences that we have observed under different, within-culture, circumstances (Andersson-Arntén \& Archer, manuscript in preparation). John and Gross (2004) have studied two commonly used emotion regulation strategies: reappraisal (changing the way one thinks about a potentially emotion-eliciting event) and suppression (changing the way one responds behaviorally to an emotion-eliciting event). They found that reappraisal has a healthier profile of short-term affective, cognitive, and social consequences than suppression. Individual-difference observations demonstrated that the application of a strategy of reappraisal in the regulation of emotions is associated with healthier patterns of affect, social functioning, and well-being than is using suppression. Finally, issues concerning the development of reappraisal and suppression and have provided new evidence for a normative shift toward an increasingly healthy emotion regulation profile during adulthood, i.e., increases in the use of reappraisal and decreases in the use of suppression, (John \& Gross, 2004).

A persistent challenge to self-report data across racial, ethnic, or cultural groups is the inherent difficulty of attaining cross-cultural comparability of key measures. Willis and Zahnd (2007) have attempted to identify different subsets of problems, including (i) translation problems, (ii) problems of cultural adaptation that impede cross-cultural comparability, and (iii) generic problems of questionnaire design that affect all groups. An important category of problems was identified that appeared to result from the interaction of respondent and question characteristics. These categories of methodological insufficiency may be assessed optimally through explicit consideration of the socio-cultural backgrounds of survey respondents, as opposed to the more usual focus on details of item translation and wording.

One limitation of the present study may associate with contextual variables linked to each respective culture that are virtually impossible to control for. Another pertains to the difficulties involving the "matching" participants with regard to respective social status, education, etc, in Indonesia and Sweden. In essence, cultural, age-related and affective status differences were observed that influenced notions of emotional regulation, e.g. through reappraisal and suppression, with particular implications for health expression, well-being and social relationships.

\section{References:}

Andersson-Arntén, A.C., Jansson, B., \& Archer, T. (2008). Influence of affective personality type and gender upon coping behaviour, mood and stress. Individual Differences Research, 6, 139-168.

Arango-Lasprilla, J. C., Ketchum, J. M., Gary, K., Hart, T., Corrigan, J., Forster, L., \& Mascialino, G. (2009). Race/ethnicity differences in satisfaction with life among persons with traumatic brain injury. NeuroRehabilitation, 24, 5-14.

Archer, T., Adolfsson, B., \& Karlsson, E. (2008). Affective personality as cognitive-emotional presymptom profiles regulatory for self-reported health predispositions. Neurotoxicity Research, 14(1), 21-44. http://dx.doi.org/10.1007/BF03033573

Archer, T., Adrianson, L., Plancak, A., \& Karlsson, E. (2007). Influence of affective personality on cognition-mediated emotional processing: Need for empowerment. European Journal of Psychiatry, 21(4), 248-262. http://dx.doi.org/10.4321/S0213-61632007000400002

Archer, T., Kostrzewa, R.M., Palomo, T., \& Beninger, R.J. (2010) Clinical staging in the pathophysiology of psychotic and affective disorders: facilitation of prognosis and treatment. Neurotoxicity Research, 18, 211-228. http://dx.doi.org/10.1007/s12640-010-9161-7

Archer, T., Oscar-Berman, M., Blum, K., \& Gold, M. (2012). Neurogenetics and epigenetics in impulsive behavior: Impact on reward circuitry. Genetic Syndromes and Gene Therapy, 3, 115-130.

Baumeister, R. F., \& Tice, D. M. (1985). Self-esteem and responses to success and failure: subsequent performance and intrinsic motivation. Journal of Personality, 53, 450-467. 
Cultural influences upon health, affect, self-esteem and impulsiveness: An Indonesian-Swedish comparison http://dx.doi.org/10.1111/j.1467-6494.1985.tb00376.x

Baumeister, R. F., Bratslavsky, E., Finenauer, C., \& Vohs, K. (2001). Bad is stronger than good. Review of General Psychology, 5, 323-370. http://dx.doi.org/10.1037/1089-2680.5.4.323

Bechara, A., Damasio, H., Tranel, D., \& Damasio, A. R. (1997). Deciding advantageously before knowing the advantageous strategy. Science, 28(275), 1293-1295. http://dx.doi.org/10.1126/science.275.5304.1293

Bensink, G. W., Godbey, K. L., Marshall, M. J., \& Yarandi, H. N. (1992). Institutionalized elderly: relaxation, locus of control, self-esteem. Journal of Gerontological Nursing, 18, 30-36.

Bjorck, J. P., Hopp, P. D., \& Jones, L. W. (1999). Prostate cancer and emotional functioning: effects of mental adjustment, optimism, and appraisal. Journal of Psychosocial Oncology, 17, 71-85. http://dx.doi.org/10.1300/J077v17n01_05

Bood, S. A., Archer, T., \& Norlander, T. (2004). Affective personality in relation to general personality, self-reported stress, coping and optimism. Individual Differences Research, 2, 26-37.

Bowman, C. H., Evans, C. E., \& Turnbull, O. H. (2005). Artificial time constraints on the Iowa Gambling Task: the effects on behavioural performance and subjective experience. Brain and Cognition, 57(1), 21-25. http://dx.doi.org/10.1016/j.bandc.2004.08.015

Butler, E. A., Lee, T. L., \& Gross, J. J. (2007). Emotion regulation and culture: are the social consequences of emotion suppression culture-specific? Emotion, 7, 30-48. http://dx.doi.org/10.1037/1528-3542.7.1.30

Butler, E. A., Egloff, B., Wilhelm, F. H., Smith, N. C., Erickson, E. A., \& Gross, J. J. (2003). The social consequences of expressive suppression. Emotion, 3, 48-67. http://dx.doi.org/10.1037/1528-3542.3.1.48

Cannella, D. T., Lobel, M., Glass, P., Lokshina, I., \& Graham, J. E. (2007). Factors associated with depressed mood in chronic pain patients: the role of intrapersonal coping resources. The Journal of Pain, 8 , 256-262. http://dx.doi.org/10.1016/j.jpain.2006.08.007

Carson, J., Keefe, F., Lowry, K., Porter, L., Goli, V., \& Fras, A. (2007). Conflict about expressing emotions and chronic low back pain: Associations with pain and anger. The Journal of Pain, 8(5), 405-411. http://dx.doi.org/10.1016/j.jpain.2006.11.004

Cohen, J. D., \& Aston-Jones, G. (2005). Cognitive neuroscience: decision amid uncertainty. Nature, 28(436), 471-472. http://dx.doi.org/10.1038/436471a

Cushman, P. (1990). Why the self is empty: Toward a historically situated psychology. American Psychologist, 45, 599-611. http://dx.doi.org/10.1037/0003-066X.45.5.599

Damasio, A. D. (1998). Emotion in the perspective of an integrated nervous system. Brain Research, Brain Research Review, 26(2-3), 83-86. http://dx.doi.org/10.1016/S0165-0173(97)00064-7

Diener, E. (2012). New findings and future directions for subjective well-being research. American Psychologist, 67(8), 590-597. http://dx.doi.org/10.1037/a0029541

Dolan, M., \& Park, I. (2002). The neuropsychology of antisocial personality disorder. Psychological Medicine, 32, 417-427. http://dx.doi.org/10.1017/S0033291702005378

Dolan, M. C., \& Rennie, C. E. (2007). Is juvenile psychopathy associated with low anxiety and fear in conduct-disordered male offenders? Journal of Anxiety Disorders, 21, 1028-1038. http://dx.doi.org/10.1016/j.janxdis.2006.11.008

Emanuele, E., Brondino, N., Bertona, M., Re, S., \& Geroldi, D. (2008). Relationship between platelet serotonin content and rejections of unfair offers in the ultimatum game. Neuroscience Letters, 437(2), 158-161. http://dx.doi.org/10.1016/j.neulet.2008.04.006

Fischer, R. \& Boer, D. (2011). What is more important for national well-being: Money or autonomy? A meta-analysis of well-being, burnout, and anxiety Across 63 societies. Journal of Personality and Social Psychology, 101(1), 164-184. http://dx.doi.org/10.1037/a0023663

Fossati, A., Di Ceglie, A., Acquarini, E., \& Barratt, E. S. (2001). Psychometric properties of an Italian version of the Barratt Impulsiveness Scale-11 (BIS-11) in nonclinical subjects. Journal of Clinical Psychology, 57(6), 815-828. http://dx.doi.org/10.1002/jclp.1051

Friedman, L. C., Nelson, D. V., Baer, P. E., Lane, M., Smith, F. E., \& Dworkin. R. J. (1992). The relationship of dispositional optimism, daily life stress, and domestic environment to coping methods used by cancer patients. Journal of Behavioral Medicine, 15, 127-141. http://dx.doi.org/10.1007/BF00848321 
Adrianson, L., Ancok, D., Ramdhani, N., \& Archer, T.

Goertzel, L., \& Goertzel, T. (1991). Health locus of control, self-concept, and anxiety in pediatric cancer patients. Psychological Reports, 68, 531-540. http://dx.doi.org/10.2466/pr0.1991.68.2.531

Gold, P. W., \& Chrousos, G. P. (2002). Organization of the stress system and its dysregulation in melancholic and atypical depression: High vs low CRH/NE states. Molecular Psychiatry, 7(3), 254-275. http://dx.doi.org/10.1038/sj.mp.4001032

Goza, F., \& Ryabov, I. (2009). Adolescents' educational outcomes: racial and ethnic variations in peer network importance. Journal of Youth and Adolescence, 38(9), 1264-1279. http://dx.doi.org/10.1007/s10964-009-9418-8

Gross, J. J., \& John, O. P. (2003). Individual differences in two emotion regulation processes: implications for affect, relationships, and well-being. Journal of Personal and Social Psychology, 85(2), 348-362. http://dx.doi.org/10.1037/0022-3514.85.2.348

Gureje, O., Harvey, C., \& Herrman, H. (2004). Self-esteem in patients who have recovered from psychosis: profile and relationship to quality of life. Australian and New Zealand Journal of Psychiatry, 38, 334-338. http://dx.doi.org/10.1080/j.1440-1614.2004.01360.x

Hashimoto, T., Mojaverian, T., \& Kim, H. S. (2012). Culture, interpersonal stress, and psychological distress. Journal of Cross-Cultural Psychology, 43(4) 527-532. http://dx.doi.org/10.1177/0022022112438396

Harter, S. (1990). Self and identity development. In S. S. Feldman and G. R. Elliot (Eds.), At the threshold: The developing adolescent (pp. 334-359). Cambridge MA: Harvard University Press.

Hofstede, G. (1980). Culture's consequences: International differences in work-related values. Beverly Hills, CA: Sage.

Hofstede, G. \& Hofstede, G. J. (2005). Cultures and organizations: Software of the mind. New York: Mc-Graw-Hill.

Izutsu, T., Tsutsumi, A., \& Matsumoto, T. (2009). Association between sexual risk behaviors and drug and alcohol use among young people with delinquent behaviors. Nihon Arukoru Yakubutsu Igakkai Zasshim, 44, 547-53.

John, O. P., \& Gross, J. J. (2004). Healthy and unhealthy emotion regulation: personality processes, individual differences, and life span development. Journal of Personality, 72, 1301-1333. http://dx.doi.org/10.1111/j.1467-6494.2004.00298.x

Karlsson, E., \& Archer, T. (2007). Relationship between personality characteristics and affect: Gender and affective personality. Individual Differences Research, 5(1), 44-58.

Keilp, J. G., Sackeim, H. A., \& Mann, J. J. (2005). Correlates of trait impulsiveness in performance measures and neuropsychological tests. Psychiatry Research, 135(3), 191-201. http://dx.doi.org/10.1016/j.psychres.2005.03.006

Kim, H. S., Sherman, D. K., \& Taylor, S. E. (2008). Culture and social support. American Psychologist, 63, 518-526. http://dx.doi.org/10.1037/0003-066X

Krain, A. L., Hefton, S., Pine, D. S., Ernst, M., Castellanos, F. X., Klein, R. G., \& Milham, M. P. (2006). An fMRI examination of developmental differences in the neural correlates of uncertainty and decision-making. Journal of Child Psychology and Psychiatry, 47(10), 1023-1030. http://dx.doi.org/10.1111/j.1469-7610.2006.01677.x

Kyngdon, A., \& Dickerson, M. (1999). An experimental study of the effect of prior alcohol consumption on a simulated gambling activity. Addiction, 94(5), 697-707.

Lakey, B., \& Scoboria, A. (2005). The relative contribution of trait and social influences to the links among perceived social support, affect and self-esteem. Journal of Personality, 73, 361-388. http://dx.doi.org/10.1111/j.1467-6494.2005.00312.x

Le, T. N., Lai, M. H., \& Wallen, J. (2009). Multiculturalism and subjective happiness as mediated by cultural and relational variables. Cultural Diversity \& Ethnic Minority Psychology, 15(3), 303-313. http://dx.doi.org/10.1037/a0015507

Lee, T. M., Leung, A.W., Fox, P. T., Gao, J. H., \& Chan, C. C. (2008). Age-related differences in neural activities during risk taking as revealed by functional MRI. Social Cognitive and Affective Neuroscience, 3(1), 7-15. http://dx.doi.org/10.1093/scan/nsm033 
Cultural influences upon health, affect, self-esteem and impulsiveness: An Indonesian-Swedish comparison

Li, C. S., \& Chen, S. H. (2007). Obsessive-compulsiveness and impulsivity in a non-clinical population of adolescent males and females. Psychiatry Research, 149(1-3), 129-138.

Li, H. C, Chan, S. L., Chung, O. K., \& Chui, M. L. (2010). Relationships among mental health, self-esteem and physical health in Chinese adolescents: an exploratory study. Journal of Health Psychology, 15(1), 96-106. http://dx.doi.org/10.1177/1359105309342601

Ljung, T., \& Friberg, P. (2004). Biology of stress reactions. Lakartidningen, 101(12), 1089-94.

Lynskey. M. T., \& Hall, W. (2001). Attention deficit hyperactivity disorder and substance use disorders: Is there a causal link? Addiction, 96(6), 815-822. http://dx.doi.org/10.1046/j.1360-0443.2001.9668153.x

Mann, R. (1997). Expats in Indonesia. Jakarta: Gateway Books.

McEwen, B. S. (2006). Sleep deprivation as a neurobiologic and physiologic stressor: Allostasis and allostatic load. Metabolism, 55(10), 20-23. http://dx.doi.org/10.1016/j.metabol.2006.07.008

Millet, P., \& Sandberg, K. (2003). Locus of control and its relationship with rehabilitation outcomes of unemployed sick leavers in Sweden. Journal of Vocational Rehabilitation, 19, 59-66.

Mohammadi, N. (2011). The factor structure of state and trait forms of positive and negative affect scales. Journal of Behavioral Sciences, 5(1), 21-26.

Nima, A.A., Archer, T., \& Garcia, D. (2012) Adolescents' happiness-increasing strategies, temperament, and character: mediation models on subjective well-being. Health, 4, 802-810. http://dx.doi.org/10.4236/health.2012.410124

Norlander, T., Bood, S. A., \& Archer, T. (2002). Performance during stress: Affective personality, age and regularity of physical exercise. Social Behavior and Personality, 30, 495-508.

Norlander, T., von Schedvin, H., \& Archer, T. (2005). Thriving as a function of affective personality. Anxiety, Stress and Coping, 18(3), 105-116. http://dx.doi.org/10.1080/10615800500093777

Oberman, R., Dobbs, R., Budiman, R., Thompson, F., \& Rosse, M. (2012). The archipelago economy: Unleashing Indonesia 'potential. Seoul: McKinsey Global Institute. Retrieved January 7, 2013, http://www.mckinsey.com/insights/mgi/research/asia/the_archipelago_economy

Oishi, S., \& Diener, E. (2001). Goals, culture, and subjective well-being. Personality and Social Psychology Bulletin, 27, 1674-1682. http://dx.doi.org/10.1177/01461672012712010

Palomo, T., Beninger, R. J., Kostrzewa, R. M., \& Archer, T. (2004). Gene-environment interplay in affect and dementia: Emotional modulation of cognitive expression in personal outcome. Neurotoxicity Research, $6,159-173$.

Palomo, T., Beninger, R. J., Kostrzewa, R. M., \& Archer, T. (2008a). Affective status in relation to impulsive, motor and motivational symptoms: personality, development and physical exercise. Neurotoxicity Research, 14(2-3), 151-168. http://dx.doi.org/10.1007/BF03033807

Palomo, T., Beninger, R. J., Kostrzewa, R. M., \& Archer, T. (2008b) Focusing on symptoms rather than diagnoses in brain dysfunction: Conscious and nonconscious expression in impulsiveness and decision-making. Neurotoxicity Research, 14(1-2), 1-20. http://dx.doi.org/10.1007/BF03033572

Patton, J. H., Stanford, M. S., \& Barratt, E. S. (1995). Factor structure of the Barratt impulsiveness scale. Journal of Clinical Psychology, 51(6), 768-774. http://dx.doi.org/10.1002/1097-4679(199511)51:6<768::AID-JCLP2270510607>3.0.CO;2-1

Potter, A. S., \& Newhouse, P. A. (2004). Effects of acute nicotine administration on behavioral inhibition in adolescents with attention-deficit/hyperactivity disorder. Psychopharmacology, 176(2), 182-194.

Proctor, C., Linley, P. A., \& Maltby, J. (2010). Very happy youths: Benefits of very high life satisfaction among adolescents. Social Indicator Research, 98, 519-532. http://dx.doi.org/10.1007/s11205-009-9562-2

Putman, P., Antypa, N., Crysovergi, P., \& van der Does, W. A. (2010). Exogenous cortisol acutely influences motivated decision making in healthy young men. Psychopharmacology, 208(2), 257-263. http://dx.doi.org/10.1007/s00213-009-1725-y

Rogers, R. D, Tunbridge, E. M, Bhagwagar, Z., Drevets, W. C., Sahakian, B. J., \& Carter, C. S. (2003). Tryptophan depletion alters the decision-making of healthy volunteers through altered processing of reward cues. Neuropsychopharmacology, 28(1), 153-162. http://dx.doi.org/10.1038/sj.npp.1300001

Rose, J. P., Endo, Y., Windschitl, P. D., \& Suls, J. (2008). Cultural differences in unrealistic optimism and 
Adrianson, L., Ancok, D., Ramdhani, N., \& Archer, T.

pessimism: The role of egocentrism. Personality and Social Psychology Bulletin, 34, 1236-1248. http://dx.doi.org/10.1177/0146167208319764

Rosenberg, M. (1965). Society and the adolescent self-image, Princeton, NJ: Princeton University Press.

Rotter, J. B. (1966). Generalized expectancies for internal versus external control of locus of reinforcement. Psychological Monography, 80, 609. http://dx.doi.org/10.1037/h0092976

Rueger, S.Y., Malecki, C. K., \& Demaray, M. K. (2010). Relationship between multiple sources of perceived social support and psychological and academic adjustment in early adolescence: comparisons across gender. Journal of Youth and Adolescence, 39(1), 47-61. http://dx.doi.org/10.1007/s10964-008-9368-6

Saalfrank, M. F., Wang, J., \& Brown, L. M. (2009). Racial and ethnic differences in preferences for healthstates and the implications for cost-utility analysis. Expert Review of Pharmacoeconomics \& Outcomes Research, 9(4), 365-373. http://dx.doi.org/10.1586/erp.09.27

Sachar, E. J., Hellman, L., Roffwarg, H. P., Halpern, F. S., Fukushima, D. K., \& Gallagher, T. F. (1973). Disrupted 24-hour patterns of cortisol secretion in psychotic depression. Archives of General Psychiatry, 28(1), 19-24. http://dx.doi.org/10.1001/archpsyc.1973.01750310011002

Sapolsky, R. M. (2005). The influence of social hierarchy on primate health. Science, 29(308), 648-652. http://dx.doi.org/10.1126/science.1106477

Sanfey, A. G., Rilling, J. K., Aronson, J. A., Nystrom, L. E., \& Cohen, J. D. (2003). The neural basis of economic decision-making in the Ultimatum Game. Science, 13(300), 1755-1758. http://dx.doi.org/10.1126/science.1082976

Scheier, M. F., \& Carver, C. S. (1992). Effects of optimism on psychological well-being: theoretical overview and empirical update. Cognitive Therapy Research, 16, 210-228. http://dx.doi.org/10.1007/BF01173489

Schmitt, D. P., \& Allik, J. (2005). Simultaneous administration of the Rosenberg Self-Esteem Scale in 53 nations: Exploring the universal and culture-specific features of global self-esteem. Journal of Personality and Social Psychology, 89(4), 623-642. http://dx.doi.org/10.1037/0022-3514.89.4.623

Someya, T., Sakado, K., Seki, T., Kojima, M., Reist, C., Tang, S. W., \& Takahashi, S. (2001). The Japanese version of the Barratt Impulsiveness Scale, 11th version (BIS-11): its reliability and validity. Psychiatry and Clinical Neurosciences, 55(2), 111-114. http://dx.doi.org/10.1046/j.1440-1819.2001.00796.x

Taylor, S. E., \& Brown, J. D. (1988). Illusion and well-being: a social psychological perspective on mental health. Psychological Bulletin, 103, 193-210. http://dx.doi.org/10.1037/0033-2909.103.2.193

Troisi, A., \& D'Argenio, A. (2004). The relationship between anger and depression in a clinical sample of young men: the role of insecure attachment. Journal of Affective Disorders, 79(3), 269-272. http://dx.doi.org/10.1016/S0165-0327(02)00406-8

Varni, J. W., Katz, E. R., Colegrove, R., \& Dolgin, M. (1994). Perceived stress and adjustment of long-term survivors of childhood cancer. Journal of Psychosocial Oncology, 12, 1-6. http://dx.doi.org/10.1300/J077V12N03_01

Veselska, Z., Madarasova Geckova, A., Gajdosova, B., Orosova, O., van Dijk, J. P., \& Reijneveld, S. A. (2009). Socio-economic differences in self-esteem of adolescents influenced by personality, mental health and social support. European Journal of Public Health, 20(6), 647-652. http://dx.doi.org/10.1093/eurpub/ckp210

Watson, D., Pennebaker, J. W., \& Folger, R. (1987). Beyond negative affectivity: measuring stress and satisfaction in the workplace. Journal of Organizational Behaviour Management, 8, 141-157. http://dx.doi.org/10.1300/J075v08n02_09

Willis, G., \& Zahnd, E. (2007). Questionnaire design from a cross-cultural perspective: an empirical investigation of Koreans and non-Koreans. Journal of Health Care for the Poor and Underserved, 18(4), 197-217. http://dx.doi.org/10.1353/hpu.2007.0118

Wirtz, D., Chiu, C., Diener, E., \& Oishi, S. (2009). What constitutes a good life? Cultural differences in the role of positive and negative affect in subjective well-being. Journal of Personality, 77(4), 1167-1196. http://dx.doi.org/10.1111/j.1467-6494.2009.00578.x 